6. Wertheimer.-The elimination of pigments by the liver. 7. Loew. - The distinction between the "active" and the " passive" albuminous material of plants.

8. Sherrington.-The varieties of leucocytes.

\section{B. Demonstrations.}

I. Chauveau.-The changes in mammalian endocardiac pressure as recorded by the tambour and air transmission method. (This classical experiment formed the main part of the afternoon's work.)

2. Gréhant.- (a) Absorption of carbonic oxide by living organisms.

3. Gréhant and Martin.-On the physiological effects of opium.

4. Wedensky.-Demonstrations with the telephone upon nerve excitation and upon voluntary muscular contraction in man.

5. Zwaardemaker.-The mechanism of smell.

Wednesday, August 3I.-Presidents: Prof. Wedensky (St. Petersburg), Prof. GrigoresCu (Bucharest).

\section{A. Communications.}

x. Cybulski.- The use of the condensor for the excitation of muscles and of nerves.

2. Hédon. - The effect of removal and of transplantation of the pancreas upon the production of diabetes mellitus.

3. Gotch.-The increased excitability of nerve and of muscle occasioned by low temperature.

4. Burch. - (a) The apparatus for photographing the movements of the capillary electrometer.

(b) The method of analyzing the electrometer curves obtained by the photographic method.

5. Burdon Sanderson. - The electrical changes in muscle as shown by the capillary electrometer.

6. Fredericq. - Autotomy in crabs.

7. Jacobi. - The muscular sense.

8. Bayliss. - The functions of the depressor nerve.

9. Doyon.-Tetanus.

Io. Wedensky. - The impossibility of causing fatigue in motor nerves.

II. Verworn.-The effect of galvanic currents on simple living organisms.

12. Moussu. - The functions of the thyroid body.

13. Slosse.-(a) The functions of the thyroid body;

(b) Autopsy of a case of thyrodectomy in the dog.

14. Kaufman. - The intra-muscular circulation.

15. De Boeck. - The effects of partial ablation of the cerebrum immediately after birth.

\section{B. Demonstrations.}

I. Waller.-The discharge of heat from the muscles of man.

2. Gotch. - The increased excitability of the sciatic nerve of the cat produced by low temperature.

3. Grigorescu.-Action of certain poisons upon the central nervous system.

4. Cybulski.--Method of stimulating muscle and nerve by means of condensor discharges.

5. Mares. - Nerve excitation by means of varying induced currents due to variations in the rapidity of magneto-induction.

6. Wedensky. - The most favourable and the least favourable frequency for effective intermittent excitation of nerve by electrical currents.

7. Paton.-A crystalline globulin obtained from urine.

In addition the following members showed instruments and models :-

I. Lahousse.-Model of the nerve centres.

2. Kosenthal.-Calorimeter with recent improvements.

3. Laulanié.-(a) A universal inscribing manometer.

(b) Apparatus for studying respiratory changes.

4. Morat. $\rightarrow$ Recording apparatus.

5. Cybulski. - The Photohæmotachometer.

6. Miescher and Jacquet.-A recording chronometer.

On Wednesday evening, at the conclusion of the proceedings, the members dined together in the large foyer of the theatre, the President of the Congress, Prof. Holmgren, being in the chair.

NO. I I 94, VOL. 46$]$
As the Congress is held every three years, the next meeting will take place in 1895, and it was decided that in response to the kind and cordial invitation of Prof. Kronecker, the meeting should be held in Berne (Switzerland).

\section{ELECTRO-METALLURG $Y$.}

THIS is not the first time a lecture has been delivered here on electro-metallurgy. I find that so long ago as January, I $84 \mathrm{I}$, there was a lecture on the subject by Mr. Brand.

At that time electro-metallurgy was very new and very small. It consisted solely of electro-plating and electrotype. Electroplating had already begun to be practised as a regular industry, but it was still a question whether the new kind of plating was good, and there were not a few silversmiths who would not offer electro-plate for sale because of its supposed inferiority to plate of the old style. That question has long been definitely settled by the fact that every week more than a ton of silver is deposited in the form of electro-plate.

Electrotype in $184 \mathrm{I}$ was not so far advanced-it had not then been taken hold of by the artisan and manufacturer-it was still in the hands of the amateur.

While the voltaic battery was the cheapest source of electric current, electro-metallurgy was necessarily restricted to artistic metal work, or to those applications where the fine quality of the electrotype cast outweighed the consideration of its cost, or where only a thin film of metal was required for the protection of a baser metal from the action of the air.

Within this limited field, the electro deposition of copper, of gold, of silver, of iron, and of nickel, has been carried on commercially with very great success and advantage for almost the whole period of the existence of the art. But beyond these bounds, set by the limitation of cost, it could not pass.

Now, all this is changed-since engineer and electrician have united their efforts to push to the utmost the practical effect of Faraday's great discovery, of the principle of generating electric currents by motive power. The outcome is the modern dynamo, with its result-cheap electricity. The same cause that has led to electric lighting, and to the electric transmission of power, has also led to a very great development of electro-metallurgic industry, and not only in the old directions but in new. It is no longer a matter of depositing ounces or pounds of metal, but of tons and thousands of tons. And it is no longer with metal deposition merely that electro-metallurgy now deals, but also with the extraction of metals from their ores, and the fusion and welding of metals. Electro-metallurgy has in fact grown so large and many-branching, that it is impossible to treat it in a complete manner in a single hour.

One of the latest developments is electric welding. This, in one of its forms, that invented by Elihu Thompson, has recently been so thoroughly explained and demonstrated by Sir Frederick Bramwell, that it is not necessary for me to do more than mention it as belonging to the subject.

There is also another species of electric welding - that of Dr. Benardos-in which the electric arc is used after the manner of a blow-pipe flame, to obtain the welding of such forms and thicknesses of iron, steel, and other metals, as would be difficult or impossible to weld in any other way; and not only is the electric blow-pipe used for welding, but also for the repair of defects in steel and iron castings, by the fusion of pieces of metal, of the same kind as the casting, into the faulty place, so as to make it completely sound. This new kind of electric welding, as improved by Mr. Howard, is now of sufficient importance to entitle it to the full occupation of an evening. I therefore propose to leave it for detailed description to some other lecturer, and content myself with calling your attention to the interesting collection of specimens on the table, and in the Library (lent by Messrs. Lloyd and Lloyd), showing the results of this process.

Even with this curtailment, the extent of the field is still too great, and I must reduce it further by omitting a considerable section of that portion which relates to the extraction of metals from their ores, and, in this connection, only speak of the extraction of aluminium

But, in the first place, I am going to speak of the deposition of copper, and you will pardon me if I treat it as if you were unacquainted with the subject.

1 Friday evening discourse delivered by Mr. J. Wilson Swan, at the Royal Institution, on May 20. 
One of the wonderful things about the electro-deposition of copper, and in fact any other metal deposited from a solution of its salt in water, is, that bright, hard, solid metal, such as we are accustomed to see produced by means of fusion, can, by the action of the electric current, be made to separate from a liquid which has no appearance of metal about it.

The beginning of every electro-deposition process is the making a solution of the metal to be deposited. I am going to dissolve a piece of copper, the most elementary of all chemical operations, but I want to make it quite clear where the metal to be deposited comes from - to show that it is actually in the solution, and actually comes out of it again; for that is an effect so surprising, that it requires both imagination and demonstration to make it evident. There is projected on the screen a glass cell containing nitric acid. $\mathrm{Mr}$. Lennox will put into it a piece of copper. He has done so; it quickly disappears, and a blue solution of copper nitrate is formed. Now, if I pass an electric current through this solution, or through some solution of the same kind, which, to save time, has been prepared beforehand, and immerse in it, a little apart from each other-the positive and negative wires coming from some generator of electric current-this will happen : metallic copper will come out of the solution, and attach itself as a coating to the negative wire, and consequently that wire will grow in thickness. At the other wire-the positive-exactly the reverse action will take place. There, if the positive wire be copper, it will gradually dissolve, and become thinner. The quantity of metal deposited on the negative wire will almost exactly equal the quantity dissolved from the positive, and therefore the solution will contain the same quantity of metal at the end of the experiment as at first, but it will not be the same metal ; it will be fresh metal dissolved from the positive wire, and the metal originally contained in the solution will have been deposited as metallic copper.

I will show on the screen thi; process in operation. Here are the two wires I spoke of. The electric circuit, which includes these two wires, is so arranged that on its completion the thick wire will be the positive, and the thin wire the negative. Now please complete the circuit. One wire (the positive) is carrying an electric current into the copper solution, and the other (the negative) is carrying the current away. The solution is conveying the current between the wires, and one of the incidents of the transport of current from wire to wire by the solution, is electro-chemical decomposition, or electrolysis ; and the result of that is, the deposition, out of the solution, of copper, upon one wire, and the dissolving away, or entering into solution, of copper, from the other. Now it can be clearly seen that the wire that was thick is now thin, and the wire that was thin is now thick.

Imagine the growing wire to be an electrotype mould, and that the deposit of copper which formed on the wire has spread over the surface and formed a nearly uniform film, and that by continuing the process it has become thick, that deposit, stripped from the mould, would be an electrotype.

Or imagine the negative wire to be a thin sheet of pure copper, and the positive wire to be a thick sheet of impure copper, and suppose the action carried on so far that the thin sheet has become thick by the deposition of copper upon it from the solution, and the thick one thin by its copper entering into solution, that case would represent the condition of things in electrolytic copper refining.

Allow your imagination to take one more short flight, and suppose that this is not a solution of copper, but one of silver, and that the growing wire is a teapot to be silvered; and, further, suppose that the dissolving electrode is silver, and you will then understand the principle of electro-plating.

It requires very little explanation to make the ordinary arrangement of electrotyping intelligible. Here is a trough containing sulphate of copper solution. Here is a mould that, through the kindness of Messrs. Elkington, has been prepared for me ; this is connected with the negative pole of a batteryand here is a plate of copper connected with the positive pole. When I immerse the mould in the solution-at about two inches from the copper plate-the electrical circuit is completed, and the same electrolytic action that the experiment illustrated will take place. Copper will be deposited on the mould, and will be dissolved in equal quantity from the copper plate, and the sup. ply of copper in the solution will thus be kept up. As it will take a little time to obtain the result $I$ wish to show, I will put this aside for ten minutes or so, and proceed to speak of different applications of this principle of copper deposition.
For the reproduction of fine works of art in metal, electrotype is unapproachable. The extreme minuteness with which every touch of graver or modelling-tool is copied by the deposited metal film, separates electrotype by a wide space from all other modes of casting. Even the Daguerreotype image is not too exquisitely fine for electrotype to copy it so perfectly that the piccure is almost as vivid in the cast as in the original.

It is this quality that has given to electrotype a rôle which no other process can fill, and, so far, its practical utility is not greatly dependent on the cost of the current. This applies to all those most beautiful things here and in the Library, lent by Messrs. Elkington. These could all have been produced commercially, even if there had been nothing better for the generation of the current than Smee's battery-a very good battery, by the way, for small operations in copper deposition. It gives a very low electro-motive force and that is a defect, but in copper deposition, the half volt or so is generally sufficient to produce, automatically, the required current destiny.

One of the uses of electrotype, not greatly affected by the cost of deposition, is that of the multiplication of printing surfaces. In these days of illustrated periodicals, electrotype has come more and more into use for making duplicate blocks from wood engravings, which would soon be worn out and useless if printed from direct. It is also employed to make casts from setup type, to be used instead of ordinary stereotype casts, when long numbers of a book have to be printed; also as a means of copying engraved copper-plates. Here are examples of all these uses of the electrotype process. The electro-blocks are lent by Messrs. Richardson and Co., and the copper-plates by the Director.General of the Ordnance Survey Office, Southampton.

The plates illustrate the method employed at Southampton in the map-printing department. The original plates are not printed from except to take proofs. The published maps are all printed from electrotypes. Here is an original plate-here the matrix, or first electro, with, of course, all the lines raised which are sunk in the original. The second electro is, like the original, an intaglio. Here is a print from it, and here one from the original plate. Practically they are indistinguishable from each other, and bear eloquent testimony to the wonderful power of electrotype to transmit an exceedingly faithful copy of such a surface.

Nickel has, of late years, come into extensive use for what is termed nickel-plating, as applied to coating polished steel and brass with nickel. Nickel not only has the advantage over silver of cheapness, but also, in some circumstances, of greater resistance to the action of the air.

Another metal, usually deposited in the form of a coating, is iron. The electrolytic deposit of iron is peculiarly hard-so much so, that it is commonly but erroneously spoken of as steelfacing. The deposition of a film of iron upon engraved copperplates, as a means of preventing the wear incidental to their use in being printed from, has become almost universal. Valuable etchings, mezzo-tints, and photogravure plates are thus made to bear a thousand or more inpressions without injury. By dissolving off the iron veil with weak acid, when the first signs of wear appear on the surface of the plate, and re-coating it with iron, an engraved copper-plate is, for all practical purposes, everlasting.

In this case, of course, the film of iron is extremely thinone or two hundred-thousandths of an inch. But it is possible to produce most of the metals commonly used as coatings in a more massive form. Here, for example, is an iron rod half-aninch in diameter, entirely formed by electrolytic deposition. I am indebted to $\mathrm{Mr}$. Roberts-Austen for being able to show this, and also for this other example of a solid deposit of iron, and for this beautiful specimen of electrolytic coating with iron. Here also are solid deposits of silver. This drinking cup is a solid silver electro-deposit.

These are all departments of electro-metallurgy which would have maintained a perfectly healthy industrial existence and growth without the dynamo; but now I come to speak of a branch of the subject-electrolytic copper refining-which, without that source of cheap electricity, could not have existed. This is the most extensive of all the applications. of electrochemistry, and is rendering valuable assistance to electrical engineering by the improvement it has led to in the conductivity of copper wire.

One of the results of this is seen in the raising of the commercial standard of electrical conductivity.

Ten years ago, contracts for copper wire for telegraphy stipu- 
lated for a minimum conductivity of 95 per cent. of Matthiessen's standard of pure copper. Now, chiefly owing to electrolytic refining, a conductivity of 100 per cent. is demanded by the buyer and conceded by the manufacturer.

To show the difference between the past and present state of things in relation to the commercial conductivity of copper, I am going to exhibit on the screen measurements of the resistance of six pieces of wire of equal length and equal cross sectionthey have been drawn through the same drawplate. Three of the pieces are new, and three are old. The three new pieces are made from electrolytic copper, and are representative of the present state of things. The three old pieces are taken from three well-known old submarine telegraph cables, and they show how very bad the copper was when it was first employed for telegraphic purposes, and how great has been the improvement. I will take No. $I$ wire as the standard of comparison. It is a piece of the wire about to be supplied to the Post Office Telegraph Department for trunk telephone lines. It will show the very high standard of conductivity that has been reached in the copper of commerce. I am indebted for it, and for two out of three of the old cable wires, to Mr. Preece. No 2 wire is made from electrolytic copper, deposited in my own laboratory. No. 3 is also electrolytic copper, but such as is commercially produced in electrolytic copper refining; it has been supplied to me by Mr. Bolton, to whom I am also indebted for wire No. 6 -a particularly interesting specimen : it is from the first TransAtlantic cable-the cable of ' 58 . No. 4 wire is from the Ostend cable of 1860 , and No. 5 wire is from the old Dutch cable. These wires are so arranged that I can send a small and constant current partly through any one of them, and partly through a galvonometer. When this is done the result will be a deflection of the spot of light on the scale from the zero point to an extent corresponding to the resistance of the particular wire in the circuit. The worse the wire is, the greater will be the deflection. We will begin with the Post Office sample first. I connect the galvanometer terminals to wire No. I; you see there is a deflection of ten degrees. I will now shift the contacts to wire No. 2-exactly the same length of wire is included -but now you see there is a deflection of slightly less than ten degrees, showing that this wire has a little lower resistance than No. I. The difference is very small-it may be 2 per cent.and 2 per cent. less of it would be required to conduct as well as the No. I wire. The next is No. 3. This is Mr. Bolton's wire, and shows a resistance almost equal to the last.

No. I, 2, and 3 are, therefore, nearly alike, and have a degree of conductivity almost as high as it can possibly be.

Now we come to the three old wires.

We will take No. 4 (the Ostend cable). There, you see, is a great difference. Instead of the spot of light being on the tenth degree, it is upon the eleventh.

We will now try No 5 (the Dutch cable). That dives the index to 17.

Now I change to No. 6 (the old Atlantic cable), and we have a deflection of no less than 25 degrees. I suppose we may assume that this wire fairly represents the commercial conductivity of copper in 1858 , for it is highly probable that for a work so important as the tirst Atlantic cable every care would be taken in the selection of the copper.

The result of this experiment shows that the copper of that cable was extremely bad as a conductor-that, in fact, it is $15^{\circ}$ per cent. worse than the best commercial copper of to-day. In other words, it shows that, in point of electrical conductivity, one ton of the copper of to-day will go as far as two-and-a-half tons of such copper as was used for the cable of ' 58 .

This change is largely due to electrolytic copper refining.

The process of electrolytic copper refining is the same in principle as that which produced the thickening of one of the wires and the thinning of the other in my first experiment. To prepare the crude copper for the refining process it is cast into slabs; these form the anodes, and correspond to the wire which in my first experiment became thin. The cathodes, corresponding to the wire which became thick, are formed of thin plates of pure copper. Here are plates such as are used in electrolytic copper refining works. They are portions of actual cathodes and anodes, and represent the state of things at the commence ment, and at the end, of the depositing operation-an operation that takes several weeks to complete, and effect the great change these plates show. In copper refining works an immense number of these plates, each having 6 to 10 square feet of superficial area, are operated upon together in a great number of large wooden vats containing sulphate of copper solution and a small proportion of sulphuric acid. Electric current from a dynamo, driven by a steam-engine or waterpower, is conveyed by massive copper conductors to the vats, arranged in long lines of 50 or ICO or more in series. Thick copper bars connect adjoining vats, and provide a positive and negative support for the plates, which hang in the solution opposite each other, two or three inches apart. During the process the impure slabs dissolve, and at the same time pure copper is deposited from the solution upon the thin plates. The deposition and dissolving go on slowly, in some cases very slowly, for a slow action takes less power, and gives purer copper than a more rapid one. The usual rate is one to ten ampères per square foot of cathode surface. You will better realise what these rates of deposit mean, when I say that one ampère per square foot rate of deposition gives for each foot of cathode surface, nearly one ounce of copper in twenty-four hours, and a thickness of one-eighth hundred of an inch ; and therefore the production of one ton of copper at that rate in twenty-four hours would require a cathode surface in the vats, in round numbers, of 36,000 square feet. At the higher rate of ten amperes per square foot, which is used where coal is cheap, one-tenth of this area would be required.

The importance of the electrolytic copper refining industry, and the extent of the plant connected with it, may be inferred from the fact that, reckoning the united production of all the electrolytic copper works in the world, nearly one ton of copper is deposited every quarter of an hour.

Very little power is required for copper deposition if the extent of the dissolving and depositing surfaces is large, relatively to the quantity of copper deposited in a given time.

Some of the impurities ordinarily found in crude copper are valuable. Silver and gold are common impurities, and these and some other impurities do not enter into solution, but fall down as black mud, axe recovered, and go to diminish the cost of the process or increase the profit; and even those impurities which enter into solution are, under ordinary conditions, almost completely separated.

Electrolytic copper refining is both an economical and an effective process. The deposited copper is exceptionally pure. At one time it was supposed that it must necessarily be quite pure, but this is not the case; other metals can be deposited with the copper, but it is not difficult to realise in practice a close approximation to absolute purity in the deposited copper. Here is an example of the deposition of a mixed metal-brass, that is, copper and zinc deposited together, and there are in the Library a number of interesting specimens of mixed metal deposition. These deposits of brass and other alloys show that more than one metal can be deposited at the same time. The great enemy to conductivity in copper is arsenic, and the deposition of arsenic as well as copper is one of the things to be guarded against in electrolytic copper refining. Not only are the chemical characteristics of electrolytically refined copper generally good, but its mechanical properties are largely controllable. Usually electrolytic copper is melted down and cast into billets of the form required for rolling and wire-drawing. This treatment not only involves cost, but the copper is apt to imbibe inpurity during fusion ; though, if the process is carefully conducted, the deterioration is slight.

But it is evident that the re-melting of the deposited copper is a thing to be avoided if possible, and the question naturally arises, why, now that deposition costs so little, may not the beautiful principle which comes into play in electrotype, and which enables the most complicated forms to be faithfully copied be taken advantage of to give to plainer and heavier objects their ultimate form ?

There are several reasons why this idea is not more frequently acted upon. One is that the process of electrolytic deposition is slow; another, that knowledge of the conditions necessary for obtaining a deposit having the required strength and other qualities, is not very widespread. Moreover, in the electrolytic deposition of copper, and indeed of all metals, there is a strong tendency to roughness on the outside of the deposit, and to excrescent growths, the removal of which involve waste of labour and material. These tendencies can to a very great extent be counteracted by careful manipulation and the use of suitable solutions, and they can also be counteracted by mechanical means. This has been done by Mr. Elmore. He remedies the faults I have mentioned by causing a burnisher of agate (arranged after the manner of a tool in a screw-cutting

No. I I 94, VOL. 46] 
lathe) to press upon and traverse a revolving cylindrical surface on which the deposit is taking place, and while it is immersed in the copper solution. The result is that it is kept smooth and bright to the end of the process.

But the use of a burnisher is not the only means available for the production of a smooth deposit. It was observed in the early days of electro-plating how great a change was effected in the character of the metal deposited by the presence of a very small quantity of certain impurities. It was found, for example, that an exceedingly minute dose of bisulphide of carbon, if put into a bath from which the silver was being deposited, caused the deposit to change from dull to bright.

I have lately had experience of a similar kind with nickel and with copper. I was working with a hot solution of nickel, and up to a certain point the deposit had the usual dead-grey appearance. Suddenly, and without doing anything more than putting in a new cathode. I found the character of the deposit completely changed. Instead of the grey, tough, adherent deposit, there was produced a brittle, specular deposit, which scaled of in brilliantly shining flakes of metal. I sought for the cause of this extraordinary change, and traced it to the accidental introduction into the solution of a minute quantity of glue.

By adding gelatine to a fresh nickel solution I obtained the same peculiar bright and brittle deposit that had resulted from the accident. I then made a similar addition to a solution of copper, and when I hit the right quantity-an exceedingly minute one-bright copper, instead of dull or crystalline, was deposited. Here are some specimens. These were deposited on a bright surface, and they are bright on both sides.

Not only is the copper made bright, under the conditions I have described, but, if the proportion of the gelatine be carried to the utmost that is consistent with the production of a brigh deposit, it becomes exceedingly hard and brittle. Beyond this point the deposit is partly bright and partly dead, the arrangement of the patches of dead and bright being in some cases very peculiar, and suggestive of a strong conflict of opposing forces.

Before I leave the subject of copper deposition, I may mention that I have found the range of current density within which it is possible to obtain a deposit of reguline metal, far wider than is commonly supposed.

The rate of deposition in copper-refining is usually very slow, and it is one of the drawbacks of the process, since slow deposition necessitates large plant. But rapid deposition necessitates a larger consumption of power, and larger cost on that account, and therefore, there is a point beyond which it is not good economy to go, in the direction ' of more rapid deposition. Still there are cases, where, if we had the power to deposit more rapidly, it might be found useful to exercise it. The subject of more rapid deposition is als o interesting from a scientific point of view, I therefore mention an unusual result I have arrived at in this direction.

Taking as one extreme, the slow rate of deposit, of one ampère per square foot of cathode-a rate not infrequent in copperrefining, I have found that the limit in the other direction is not reached by a rate of deposit one thousand times faster. I have produced, and I hope to be able to produce before you, a perfectly good deposit of copper, with a current density of 1000 ampères per square foot of cathode.

This cell contains a solution of copper nitrate with a small proportion of ammonium chloride. The plate on which I am going to produce a deposit of copper has an exposed surface of 21 square inches. Opposite, at a distance of one inch, is a plate of copper. When I close the circuit, a current of 140 ampères is passing through the solution. I continue this for just one minute. Now I wash it and remove the outer edge so as to detach the deposit, and as you see, I have a sheet of good copper -an electrotype.

To have produced a deposit of this thickness at the ordinary rate used in electrotyping operations would have occupied more than an hour.

In this experiment an extreme degree of rapidity of deposition has been shown. I do not intend to suggest such a rate of practical value. But it is at least interesting, as showing that the characteristic properties of copper are not less perfectly developed when the atoms of metal have been piled up one on the other at this extremely rapid rate than when there is slower aggregation.

I think it probable that a rate of deposit intermediate between this rate and the usual one of about Io ampères per square foot may frequently be useful, for no doubt the slowness of the rate of deposit has often prevented electrotype from being made use of where, if the rate could have been increased ten times, it might have been used with advantage.

Here are some thick plates, deposited at the rate of 100 amperes per square foot. They are as solid and as free from flaw as plates deposited ten times more slowly.

I sair that electrolytic copper-refining owed its existence to the discovery and improvement of the dynamo, and that other electro-metallurgic industries hadoriginated from the same cause. One of these industries is the electrolytic production of aluminium.

When Deville produced aluminium by the action of sodium on aluminium chloride, exaggerated expectations were entertained of the great part it was about to play in metallurgy. It was very soon found that aluminium had not all the virtues that its too sanguine friends had claimed for it, but that it had a great many most valuable properties, and, given a certain degree of cheapness, a number of useful applications could be found for it. Some of these are suggested and shown by the various articles made of aluminium, kindly lent by the Metal Reduction Syndicate, and metallurgical research is rapidly extending our knowledge of its importance in connection with the improvement of steel castings, and the production of bronzes and other alloys of extraordinary strength. The cost of aluminium produced by Deville's process was too great to permit of its use on any large scale for these purposes.

After Davy demonstrated, by the electrolytic extraction of potassium and sodium, the power of the electric current to break down the strong combination existing between the alkaline metals and oxygen, it seemed natural to expect that aluminium would also be reduced by the same means. But Davy did not succeed in producing any appreciable quantity of aluminium by the electrolytic method. Deville and Bunsen were more successful, but they did not possess the modern dynamo: that has made all the difference between the small experimental results they achieved and the industrial production of to-day, a production now so large that I suppose every day it amounts to at least one ton, and has resulted in a very great reduction of the price of the metal.

There are two electrolytic processes at work. One is the Hall process-employed at Pittsburg, and at Patricroft, Manchester-and now in experimental operation here. The other, the Herault process, worked at Neuhausen, is not greatly different from the Hall process-the shape of the furnace or crucible is different, and the composition of the bath yielding the aluminium may be different, but in all essentials these two processes are one and the same. They depend on the electrolysis of a fused bath, composed of cryolite, aluminium fluoride, fluorspar, and alumina. In the Hall process this mixture is contained in a carbon-lined iron crucible-the cathode in an electric circuit; and between which and the anode-a stick of carbon immersed in the fused bath-a difference of potential of Io volts is maintained. In carrying out the process on a manufacturing scale, there are many of these sticks of carbon to each bath. Here, in our experimental furnace, there is only one.

The heat developed by the passing of so large a current as we are using (180 amperes) through an electrolyte of but a few inches area in cross section, is sufficient to melt and keep redhot the fluorides in which the alumina is dissolved.

The electrolytic action results in the separation of aluminium from oxygen. The metal settles to the bottom of the pot, and is tapped or ladled out from time to time as it accumulates. The oxygen goes to the carbon cylinder, and burns it away at about the same rate as that at which aluminium is produced. It is only necessary to keep up the supply of alumina to enable the operation to be continued for a long time. I mean, of course, in addition to the keeping up of the current and the supply of carbon at the anode.

By far the greater part of the cost of aluminium obtained by electrolysis is the cost of motive power : 20 horse-power hours are expended to produce I pound of aluminium. Therefore it is essential for the cheap production of aluminium to have cheap motive power.

There is one feature about the Neuhausen production of aluminium which is very striking, and that is the generation of the electric current by means of water power derived from a portion of the falls of the Rhine at Schaffhausen.

The motive for making use of water power is economy. But, apart from that, it is interesting to see water replacing coal, not only in the production of power, but also in the production. of the heat required in a smelting furnace. 
Here is the Hall apparatus on a small scale. It is simply a carbon-lined iron crucible, and a thick stick of carbon. As already mentioned, the crucible is the cathode, the stick of carbon the anode.

As the process takes time to get into full operation, it was commenced some hours ago, and at the rate at which it has been working we should by now have produced several ounces of aluminium. In beginning the process the charge has first to be melted. This is done by bringing the carbon stick into contact with the bottom of the crucible, so as to allow the current to pass from carbon to carbon to develop heat between the electrodes.

The alumina compound, which, when melted, forms the bath, is added, in powder, little by little, and, when sufficient is melted, the carbon stick is raised out of contact with the bottom, and the electrolytic action then commences.

I will now ask Mr. Sample to empty the crucible and let us see the result of the operation, and while he is doing so I take the opportunity of expressing my very sincere thanks for his having so kindly and so successfully carried out this most interesting demonstration of the latest and one of the most important of all the applications of electricity to metallurgical operations.

Here is the result of our experiment. It is not very large certainly, but it is quite enough for our purpose, which is to illustrate the principle of a newly developed electro-metallurgical industry directly derived from discoveries made at the Royal Institution.

\section{MOUNT MILANJI IN NYASSALAND.}

HIDDEN in the recesses of one of the recently issued Parliamentary Papers (Africa, No. 5, 1892) will be found a very interesting report on the mountain and district of Milanji, in British Central Africa, by Mr. Alexander Whyte, F.Z.S., one of Mr. Commissioner Johnston's principal assistants in the task of ruling and developing the new British Protectorate of Nyassaland. Mr. Whyte was sent to Milanji by Mr. Johnston in October last, and dates his report from the "Residency, Zomba, British Central Africa," in the month following. Milanji is a large mountain mass in the extreme south-east corner of Nyassaland, drained on the west by the head waters of the Ruo, one of the affluents of the Shiré, and on the east by the Lukuga and other smaller streams, which run into the Indian Ocean north of the Zambesi. It is described by Mr. Whyte as an isolated range of, for the most part, precipitous mountains, the main mass forming a huge natural fortress of weather-worn precipices or very steep rocky ascents, sparsely clothed with vegetation. Many of its gullies and ravines are well wooded, and in some of them fine samples of grand African virgin forest are met with. Mr. Whyte's ascent, on the 2oth of October, was made up the south-east face of Milanji, over steep grassy hills and across rocky streams, full of large water-worn granite boulders. Further on precipices were encountered, and it was necessary to clamber up, holding on by tufts of grass, roots, and scrub, after which a wooded gorge was entered, and welcome shade was obtained from the forest trees.

Here an interesting change in the vegetation was at once perceptible, the plants of the lower slope being mostly replaced by other species. These in many cases approached the flowers of temperate climes, such as brambles and well-known forms of Papilionacea and Composita. Ferns, too, became more numerous, and now and again were encountered perfect fairy dells of mosses, Selaginellas, and balsams, with miniature water-falls showering their life-giving spray on the little verdant glades, while overhead hoary lichens and bright festoons of elegant longtasselled Lycopods hung from the moss-covered trees. After they had passed through some dense thickets of bamboo, and climbed up an ugly barrier of precipitous cliffs, another hour's ascent, the latter part of which was through a steep grassy glen, brought Mr. Whyte and his companions to the highest ridge of Milanji.

Hence was a splendid view over rolling hills of grassy sward divided by belts of dark-green forest, and the climate was found to be delightfully cool and bracing, with a clear dry atmosphere of about $60^{\circ} \mathrm{Fahr}$. Altogether two weeks were spent at three different sites on this high plateau, and good collections of its natural history were made, although rain and mist occasionally interfered with the operations of the naturalists.

The flora of the mountain proved to be of great interest, being quite distinct from that of the surrounding plains, and even from that of the lower slopes. Tree-ferns were found to attain a great size in the damp, shady forest, and one was measured 30 feet in height and 2 feet in diameter at its base. The display of wild flowers is described as "gorgeous." Creamy-white and yellow helichrysums mingled wilh purple and blue orchids and irises, and graceful snow-white anemones were all blooming in wild profusion, and rearing their heads from a bed of bright green grassy sward. But the most striking botanical feature of the Plateau of Milanji was the cypresses formerly apparently quite abundant, but now confined to a few of the upper ravines and valleys, where the annual bush-fires, which take place in the dry months of August and September, cannot reach them. In some places hundreds of these giant trees thus destroyed lay prostrate, piled one above another, in every stage of destruction. One of these dead conifers was found to measure 140 feet in length and $5 \frac{1}{2}$ feet in diameter at 5 feet from its base. The foliage of this cypress is juniperlike. The timber, of a dull reddish-white colour, is of excellent quality and easily worked. Ripe cones of this fine tree were procured, and, as stated in a subsequent letter, have already germinated in the experimental garden at Zomba. ${ }^{1}$

The fauna of the mountain was found to be of nearly equal interest to the flora, but in the short space of time available it was not possible to make so nearly a complete collection. Raptorial birds were very scarce, but Passeres were plentiful. The grassy lands of the summits were tenanted by a small dark brown quail, a pipit, two grass-warblers, and the ubiquitous great-billed raven (Corvultur albicollis), which, however, was not so numerous as on the plains below. In the adjoining forest bird-life was abundant. Bul-buls, fly-catchers, warblers, finches, and honey-birds joined in chorus in celebrating the springtime and nesting season, which was then in full progress. Altogether about 200 specimens of birds were obtained. Of mammals few were met with. The beasts of prey consisted of the leopard, the spotied hyæna, the serval, and an ichneumon. Examples of three species of Muride were also obtained, and a little antelope, probably of the genus Neotragus, was observed, but not procured. A few snakes were likewise met with.

As regards the question of establishing a sanatorium on the Milanji Plateau, to which special attention had been directed, Mr. Whyte has no hesitation in saying that the climate of this district contrasts very favourably with that of some of the hillstations in India and Ceylon. The year is pretty equally divided between wet and dry months, the former lasting from November till May, while the other six months are stated to be fine, clear, and bracing, the thermometer at night in the months of May, June, and July occasionally falling below the freezing point. In the month of October the air was found to be delightfully pure and balmy. We believe that steps have already been taken to build a small station on Milanji, but to render this of much use it will be necessary to form a road to it from the falls of the Ruo up the Lutshenya valley. This could be made with fairly good gradients, and would be of great advantage as an outlet for the cypress-timber, which now lies useless and decaying in the forest.

We are pleased to be able to add that Mr. Whyte's collections above spoken of, along with others from Mount Zomba, have already reached London, and are in the hands of Mr. Sclater, to whom Mr. Johnston has entrusted the task of getting them worked out and described. Mr. Oldfield Thomas has already commenced to determine the mammals, Captain Shelley will name the birds, and Mr. Boulenger, it is believed, will undertake the examination of the reptiles and batrachians. The plants will be examined in the Botanical Department of the British Museum, in which institution Mr. H. H. Johnston has directed the first set of specimens in every department to be deposited. The zoological results will be published in the "Proceedings" of the Zoological Society of London.

\section{OBSERVATIONS OF THE PLANET MARS."}

I OUGHT to have written to you before on the subject of the planet Mars, which I have been studying for over four months with our great equatorial. My great desire to verify the

I Some cones of this supposed "Cypress" have also reached the Botanical Department of the British Museum, and have proved to belong to a Conife of the genus Widdringtonia, prubably of a new species. But this poin cannot be definitely settled until more perfect specimens of the tree have been received.

${ }_{2}^{2}$ Letter from M. Perrotin to M. Faye, Comptes rendus, September 5.

NO. 1 I 94, VOL. 46] 